\title{
Revista

\section{A encenação do olhar no cinema da Nouvelle Vague}

\section{The staging of the gaze in the cinema of Nouvelle Vague}

LUIS HENRIQUE BOAVENTURA

Mestre em Letras pela Universidade de Passo Fundo (UPF).

<luis@consultordetextos.com>

ERnani Cesar de Freitas

Professor do Mestrado em Letras da Universidade de Passo Fundo (UPF). Professor do Mestrado em Processos e Manifestações Culturais (FEEVALE).

<ecesar@upf.br>

\section{RESUMO}

Em meados da década de 50, o cinema clássico americano entrava em crise, enquanto na França surgia a Nouvelle Vague, movimento cinematográfico liderado por jovens diretores e ex-críticos da revista Cahiers du Cinéma. Nomes como Jean-Luc Godard e François Truffaut promoviam a chamada "política dos autores", que defendia a inclusão do diretor de cinema no panteão dos indivíduos-artistas, como pintores e escritores. Este trabalho aborda o discurso velado de defesa dessa política através dos filmes da Nouvelle Vague, que enunciavam a presença de seu diretor enquanto artista por trás da obra. Esse discurso era defendido através do olhar lançado para a câmera, um olhar que interpela e desafia o espectador. Nosso objetivo é investigar as práticas discursivas que evidenciaram essa tendência do cinema francês da época para reafirmar-se enquanto arte e enquanto produto do individualismo de alguém a quem se poderia chamar, tal qual ocorria nas outras artes, de "autor".

Palavras-chave: Enunciação. Cinema. Nouvelle Vague.

\section{ABSTRACT}

In the mid-50s classic American cinema went into crisis, while in France appeared the Nouvelle Vague film movement led by young directors and former critics of Cahiers du Cinéma. Names like Godard and François Truffaut promoted the so-called "policy of authors", who advocated the inclusion of film director in the pantheon of individual-artists, like painters and writers. This paper addresses the veiled discourse defense of this policy through the films of the Nouvelle Vague, which articulated the presence of its director as an artist behind the work. This speech was defended by the gaze turned to the camera, a gaze which questions and challenges the viewer. Our goal is to investigate the discursive practices that showed this trend in French cinema of the time to reassert itself as art and as a product of the individualism of someone who could be called, as it occurred in the other arts, the "author".

Keywords: Enunciation; cinema; Nouvelle Vague. 
$\mathrm{O}$ olhar para a câmera implica uma questão não apenas linguística, mas especificamente enunciativa. Este olhar vertical, subterfúgio proibido em uma concepção canônica de cinema, é forte marca de enunciação com o poder de localizar seu personagem entre dois mundos (o real e o fílmico) e chamar a atenção do espectador para sua própria condição: a de um espectador, a de alguém que não vive a trama, apenas assiste a um espetáculo engendrado por terceiros.

Procuramos reavivar a aplicação da enunciação sobre o cinema a partir do olhar para a câmera enquanto marca enunciativa, elemento que, sob este prisma, carece de um estudo mais cuidadoso. A questão norteadora deste artigo é a seguinte: de que maneira o olhar para a câmera, enquanto marca de enunciação, é posto em uso no cinema e que efeitos ele pretende? Como veremos, tanto para fins narrativos, para a confirmação de um argumento, quanto para uma aparente gratuidade (que esconde forte intenção de seu realizador), o olhar para a câmera revolve todo um novo patamar narrativo no filme analisado.

O objetivo geral abrange analisar o funcionamento do olhar para a câmera à luz da enunciação. Nossos objetivos específicos são examinar os diferentes casos e contextos em que esse recurso se aplica e avaliar se a distinção da natureza dos casos acarretará também uma distinção em seus efeitos.

O marco teórico do trabalho é a enunciação aplicada ao cinema por Christian Metz, em especial a enunciação impessoal, passando também pela enunciação de Benveniste, mais especificamente a dinâmica locutor/alocutário descrita em $O$ aparelho formal da enunciação (1974) e a dicotomia história/discurso. Para essa última foram trazidas referências paralelas e respectivos leitores, como Ismael Ângelo Cintra, além da obra A estética do filme (1995), organizada por Jacques Aumont e que contém textos de Alain Bergala, Michel Marie, Marc Vernet e do próprio Aumont. Dessa obra retiram-se ainda, 
acepções gerais acerca da enunciação no cinema e das questões relativas à linguagem cinematográfica.

A pesquisa caracteriza-se como descritiva e bibliográfica; a abordagem é do tipo qualitativa. A análise pautou-se pelos seguintes procedimentos: foram feitas as leituras dos textos de Benveniste e, em seguida, a leitura da obra de Aumont. Foram realizadas também pesquisas na internet onde houve acesso aos demais materiais. Procedeu-se, em seguida, à análise do corpus, composto pelo filme francês $O$ demônio das onze horas, de Jean-Luc Godard (Pierrot le fou, 1965).

Este estudo organiza-se em duas seções, sendo a primeira dividida em quatro subseções. 1 Encenação e enunciação do olhar que realiza um breve apanhado da aplicação da teoria da enunciação sobre o cinema e como ocorre o apagamento de vestígios a fim de proteger a ilusão de objetividade do relato. Ela se divide em 1.1 A enunciação impessoal, 1.2 História e discurso, 1.3 Diegitização e 1.4 O olhar para a câmera. A seção 20 olhar para a câmera por Jean-Luc Godard a qual visa a uma investigação sobre o uso da enunciação através do olhar direto para a câmera: de que modo ele pode ser encenado; com que efeitos e objetivos.

\section{Encenação e enunciação do olhar}

A possibilidade da enunciação aplicada ao cinema surgiu por concepção do teórico francês Christian Metz no início da década de 70. Metz chamou a atenção para uma consciência da imagem de si mesma e uma autoconsciência do espectador, inscrevendo assim uma dinâmica de interdependência entre ambos. Segundo Metz (apud Gardies, 2006, p. 28), "a enunciação é o ato semiológico pelo qual certas partes de um texto nos falam desse texto como se fosse um ato". A porção que nos cabe é analisar a ruptura e a força de um ato específico: o olhar dirigido para câmera, uma marca de enunciação de grande poder dentro da narrativa cinematográfica. 
É importante lembrar que, em princípio, não havia esse estranhamento com relação ao olhar do ator na direção do público. Ainda incipiente, pelo menos até o começo dos anos 1920, o cinema tinha não apenas por base, mas por referência mimética, o teatro. Faltava-lhe um aparato de expressão, um modus operandi que lhe fosse próprio. Muitos dos primeiros filmes resumiam-se a uma câmera estática que registrava a ação semovente diante de si, emulando a presença do espectador, resignado em seu lugar na plateia. O cinema primitivo era em muito a representação de uma arte anterior. Foi somente a partir dos contributos de D. W. Griffith e S. M. Eisenstein (Marie, 1995, p. 169), passando por Dziga Vertov e seu manifesto do Cinema-verdade Kino-Pravda, Um homem com uma câmera (1929), que se foi revelando a silhueta do que constituiria mais claramente a linguagem cinematográfica, desligando o cinema das artes às quais era, por assim dizer subordinado, como o teatro e a literatura.

Esse processo misto de independência e de afirmação enquanto arte faz o cinema desenvolver-se sob a norma de um apagamento de si mesmo, de seus processos. A primeira metade do século XX viu um cinema que impunha todas as suas forças para disfarçar os mecanismos do espetáculo, elegendo a ilusão da sala escura como instituição a ser blindada, como um castelo de areia que, a despeito da obsessiva confecção dos detalhes que legitimam sua própria representação da realidade (com o negar, portanto, da própria representação, como se significante e significado fossem um só), desmonta-se ao mais delicado sopro de vento.

A câmera, a partir deste momento, em especial no cinema clássico americano ${ }^{1}$ (valendose muito das inovações de Orson Welles em Cidadão Kane (1941), empregará toda trucagem e subterfúgio possível para disfarçar a existência dos mesmos, o que aponta para a ironia da sua natureza: quanto menos se lança mão desses artifícios, quanto menos se movimenta a câmera e quanto menos se impõe o corte na sala de montagem, mais explícita ficará a onipresença de um aparato técnico e de uma encenação. 
A câmera primitiva, aquela imóvel que simplesmente registrava a ação diante de si, caía na contradição de marcar indelevelmente sua própria presença física. A câmera parada joga ênfase sobre a existência de um espectador e, por consequência, sobre a existência do espetáculo. Não havia ali um dos fundamentos básicos da linguagem cinematográfica: a abstração do espectador, a ilusão de se deixar tragar por este segundo universo que se dimana na tela.

A escritura de uma linguagem própria ao cinema pressupunha, por necessidade, o apagamento da câmera para que o próprio espectador pudesse tomar seu lugar. Se há um olho que capta a cena, esse olho não pode ser alheio, não pode haver uma intermediação para que o truque funcione corretamente.

O espectador de cinema, encarnado nessas lentes e conduzido pela atmosfera fílmica como um ente alado e invisível, observador ubíquo da fantasia, perde a consciência de si mesmo. O espectador ideal do cinema clássico é aquele que não toma nota de si, que não se percebe, condição essa para que se mantenha intacta a delicada ilusão da caixa de luz e sombra. A câmera é um paradoxo, opera exaustivamente para desfazer os próprios rastros, atingindo nesse estágio uma capacidade que a define como veículo de uma arte única: a de contar uma história ${ }^{2}$, a de enunciar sem a postulação de um alocutário, sem permitir troca linguageira. Christian Metz, em artigo publicado em 1991, chamou esta modalidade de enunciação impessoal.

\subsection{A enunciação impessoal}

A dificuldade inicial enfrentada ao aplicar o conceito de enunciação ao cinema surgiu de um simples emprego pronominal. Quem é o eu e quem é o tu na projeção de um filme? Na teoria da enunciação, elaborada por Benveniste nos anos 1960, há um eu e um $t u$ que se alternam na troca de linguagem - é esta a raiz do aparelho enunciativo. Ocorre que no cinema, como sabemos, não há troca, não há diálogo, apenas uma 
obra finalizada que fala a um sujeito condenado indefinidamente a uma posição de passividade (de espectador). Não se soube a princípio determinar o lugar desse produtor da mensagem no filme. Trata-se do diretor? Do roteirista? Do personagem? Christian Metz resolveu muitas dessas questões em seus primeiros trabalhos.

Todo filme põe um discurso em funcionamento através de uma série de aparatos de encenação, logo, todo filme enuncia de uma forma ou de outra. Metz (1991) chegaria à conclusão, na companhia de outros teóricos da linguagem como Marc Vernet (1989) e Francesco Casetti (1991), de que embora conflite com o modelo inicial de Benveniste, a enunciação no cinema é imanente e perfeitamente cognoscível, basta aceitar que sua natureza, ao contrário do que ocorre no diálogo, é impessoal (o emprego dos pronomes, nesse caso, serve apenas a um propósito de ilustração).

Qualquer recurso de mise en scène $e^{3}$ recai sobre a questão da impessoalidade da enunciação: quando o aparato de cena é exposto no espelho da boate, em Dublê de corpo (Brian De Palma, 1984), o filme enuncia uma determinada mensagem, em termos linguísticos, impessoal (pode-se, é claro, evocar a figura de De Palma, mas é preciso lembrar que a peça de enunciação em si, que a léxis do ato de linguagem, é o filme; daí, portanto, a impessoalidade). Do mesmo modo, toda decisão criativa aliada mesmo a elementos menos influentes mas não desprezíveis, como a composição dos atores ou a escolha da paleta de cores da fotografia, configura uma certa maneira de enunciar. Por que foi escolhido este enquadramento específico no lugar de outro (ou por que não foi escolhido enquadramento algum)? Por que o uso do zoom no lugar do travelling, ou vice-versa? Por que o corte agora e não dois segundos mais tarde?

A mise en scène abriga procedimentos de enunciação. $O$ filme sempre tem algo a dizer em sua própria linguagem, por isso dá-se ao luxo de dispensar notas de esclarecimento e narradores, por isso os personagens não "sentem" a necessidade de virar-se para a câmera para explicar o que está acontecendo. É em razão disso que o olhar para a 
câmera é um recurso extremo, raro, que possui um efeito muito forte em cena. Em uma arte cuja natureza de sua linguagem admite uma enunciação que é impessoal, o olhar para a câmera pode ser apontado como a grande marca de pessoalidade, como um traço inegável de processo enunciativo que pode trazer de volta a configuração de história que o cinema clássico assume para a configuração de discurso (como veremos ocorrer no caso analisado em nosso corpus).

Marca-se aqui história de um lado e discurso de outro, conforme consagrada oposição de Émile Benveniste, implicando naturalmente objetividade e subjetividade do enunciado. Como explicou Vernet, essa ausência da câmera, esse disfarce por sobre mecanismos e componentes que constroem o filme permitem ao cinema um espelhamento com a gratuidade e imprevisibilidade da própria vida.

O filme de ficção tira algumas vantagens de se apresentar como uma história (no sentido em que Benveniste compreende isso). Apresenta-nos, em suma, uma história que se conta sozinha e que, com isso, adquire um valor essencial: ser como a realidade, imprevisível e surpreendente [...]. O caráter de verdade permite-lhe mascarar o arbitrário da narrativa e a intervenção constante da narração, assim como o caráter estereotipado e organizado do encadeamento das ações."

Trata-se da evolução natural do truque: a farsa que acoberta seus vestígios e leva à ilusão pura da realidade, o cinema em que a narrativa eficaz equivale a uma mentira 
bem contada, ou uma "meta-mentira": alguém conta (ficção), mas finge não contar. Ou seja, emulando a concepção de história de Benveniste, inventando para o discurso uma objetividade como ferramenta de legitimação do próprio discurso, conceitos que veremos a seguir.

\subsection{História e discurso}

A dicotomia história $\mathrm{x}$ discurso provém dos trabalhos de Benveniste no campo da narratologia. O primeiro elemento é hoje mais comumente referenciado como narrativa, segundo trabalhos de Gérard Genette. Seguiremos, porém, utilizando história em detrimento de narrativa para conservar um referencial mais claro a Benveniste e para não causar confusão para com a narrativa cinematográfica e seus desdobramentos teóricos, evitando assim um risco desnecessário de desvirtuamento.

Benveniste define história como "a apresentação de eventos em algum ponto do tempo sem a intervenção do locutor no relato" (1995). Discurso, por outro lado, é "qualquer pronunciação supondo um locutor e um alocutário em que haja a intenção de influenciar o outro de alguma maneira" (apud Cintra, 1981, p. 51). Trata-se aqui da questão da objetividade e da subjetividade do récit.

A história não é a forma natural da comunicação, portanto não basta narrar sem intervir para constituir um relato objetivo. Essa "intervenção" aqui praticada não é, na maioria das vezes, uma opção ponderada. Para produzir um relato enquanto história, um enunciado limpo de indícios, é preciso ação para apagar as próprias marcas de enunciação, ou seja, os índices dêiticos que se deixam transparecer no relato.

O discurso é, ao contrário, a naturalidade plena da linguagem, porque pressupõe a liberdade para enunciar, instituindo a subjetividade que marca a si mesma sem deliberação. "É na linguagem e pela linguagem que o homem se constitui como sujeito; porque só a linguagem fundamenta na realidade, na sua realidade que é a 
do ser, o conceito de ego" (Benveniste, 1966, p. 286). O discurso é a fórmula natural da enunciação porque comporta todo o aparato que a define, que marca o sujeito no mundo.

O discurso é assumido. O discurso não é discurso a não ser que esteja relacionado a uma instância que, ao mesmo tempo, se põe como fonte de pontos de referência pessoais, temporais, espaciais e indica qual atitude adota em relação àquilo que diz a seu interlocutor."

(Charaudeau; Maingueneau, 2008, p. 171)

O discurso prescinde de vigilância; a história, ao contrário, demanda um trabalho constante sobre o relato, que se modifica concomitantemente à própria realização para firmar a ilusão de que está se contando sozinho. Enquanto o discurso abre-se à dinâmica referencial e sui-referencial do eu/tu, a história, necessariamente, lançará mão da não-pessoa ele, assim definida por Benveniste (1966, p. 286).

A história é o terreno da terceira pessoa; exige a supressão dos índices dêiticos e demais resquícios de subjetividade em sua concepção, portanto, seu locutor não pode jamais permanecer passivo enquanto relata, pelo mesmo motivo que a câmera não pode permanecer estática enquanto filma. A falta de ação acarreta, evidentemente, a naturalidade da linguagem, seu fluxo liberto e incontido. A câmera (não como objeto, mas como instituição fílmica, como ferramenta de enunciação de seu diretor) precisa operar subterfúgios para apagar sua própria presença, precisa intervir para simular a objetividade, para vendê-la ao espectador a fim de protegê-lo dessa tomada de 
consciência que o leva a perceber: "eu sou um espectador", logo, "estou assistindo a uma obra de ficção". A história é, desse modo, não apenas uma modalidade do próprio discurso, mas a princípio sua forma mais artificial de relato. Nada se conta por si mesmo. Para forjar essa impressão de conto espontâneo, aplica-se o que se convencionou chamar teoria de diegitização.

\subsection{Diegitização}

Contrariando o percurso natural da linguagem, a objetividade da história, para se afirmar, exige uma operação constante de apagamento dos índices e referentes que denunciam a presença de um locutor, de alguém que a conta (ou que a narra, efetivamente). No que tange ao cinema, o obscurecimento dessas presenças fantasmáticas da narração se imbrica a um processo de absorção desses referidos elementos pela diegese. $\mathrm{O}$ que não puder ser apagado será assimilado pelo universo diegético.

A diegese é um conceito próprio da narratologia. Charaudeau e Maingueneau (2008, p. 343) a definem como "a história contada como conteúdo e mais amplamente o mundo que se propõe e constrói cada narrativa: o espaço e o tempo, os eventos, os atos, as palavras e os pensamentos das personagens". Pode-se falar ainda, visando a uma maior precisão ao se tratar de cinema, em universo diegético - um segundo universo, pressupondo de imediato a oposição ao primeiro (primário), o universo de fato, aquele em que habita o espectador. É para uma absorção do primeiro pelo segundo que o cinema emprega técnica e mise-en-scène.

O processo de diegitização seria, assim, a apreensão que o universo diegético faz de elementos concebidos no universo real, peças da linguagem cinematográfica que lhe são notadamente externas, que operam do lado de fora do mundo dos personagens. Segundo Vernet, 
[...] a organização do filme narrativo clássico leva muitas vezes a fenômenos de diegitização de elementos que não pertencem de fato à narração. Acontece, de fato, que o espectador seja conduzido a atribuir à diegese o que é uma intervenção notável da instância narrativa do desenvolvimento da narrativa."

(1995, p. 120)

O exemplo mais óbvio de elemento extradiegético é a trilha, uma imposição evidentemente externa que se sobrepõe à ação corrente na tela. Os atores ignoram sua existência; apenas o espectador realmente ouve a trilha. De fato, no início do século XX, as sessões de cinema mudo (das décadas de 10 e 20 até a primeira metade dos anos 1930) costumavam ser acompanhadas por um pianista ou violinista, presente na sala, que executava melodias guiadas pelo que se passava na tela.

Apesar de a técnica ter evoluído, esse caráter marginal, extracorpóreo da trilha permanece o mesmo. Por opção, contudo, é possível incluir a trilha na diegese e permitir inclusive que os atores interajam com ela. Os musicais, prolíficos no cinema americano desde o advento do filme falado, baseiam-se muitas vezes nessa introdução da trilha ao universo diegético. Um caso mais representativo, que pode nos servir melhor como ilustração (saindo do campo do musical, um gênero especial por ter na trilha seu fulcro), é o do western spaghetti ${ }^{4}$ Era uma vez no oeste (1968), do diretor Sergio Leone. No filme, a trilha composta por Ennio Morriconi é frequentemente executada pelo próprio protagonista, que carrega consigo uma harmônica o tempo todo. A música é compartilhada pelo espectador e pelos personagens. Nesse caso, o 
elemento que era extradiegético salta da realidade para a ficção na tela, tornando-se intradiegético.

Marc Vernet define pela diegitização a "eficácia do cinema clássico americano", que pretendia diluir na diegese os resquícios de sua mecânica.

No cinema clássico, tende-se a dar a impressão de que a história está se contando sozinha, por conta própria, e que narrativa e narração são neutras, transparentes: o universo diegético finge se oferecer aí sem intermediário, sem que o espectador tenha o sentimento de que deve recorrer a uma terceira instância para compreender o que está vendo."

(Vernet, 1995, p. 120)

No entanto, como já pontuado, a história enquanto forma de relato é não mais que uma modalidade da narração, uma estratégia adotada com um fim específico (no caso, o de apagar vestígios da existência da própria narração). Vernet (1995, p. 121) sentencia em seguida: "o filme de ficção clássico é um discurso [...] que se disfarça de história". Não pode haver história sem a instância de um contador de histórias (Gaudreault; Jost, 2011, p. 1) essa é uma noção básica em narratologia. Se a maquilagem sobre a narração é por ironia a indelével confirmação do narrador, o cinema viria a "descobrir", ainda no cinema clássico americano em menor grau, mas, principalmente, a partir da Nouvelle Vague ${ }^{5}$, que marcar a instância da narração poderia ser uma opção estilística deveras interessante. É onde mora a relevância artística do olhar para a câmera como recurso de estilo. 


\subsection{O olhar para câmera}

De todos os possíveis traços de subjetividade presentes em um filme, como a trilha, a montagem, o narrador-personagem, efeitos de computação gráfica; ou, no âmbito da câmera, o enquadramento, a composição de sombras em um plano (artifícios a partir dos quais Christian Metz primeiro argumentou que por determinadas marcas a imagem chama a atenção para sua própria natureza), o olhar para a câmera é o mais simples e o mais radical, é a marca de enunciação por excelência no cinema porque instaura, explícita e inexoravelmente, a dêixis na narrativa.

[...] supõe-se tradicionalmente que a forma discursiva eu/tu vem acentuar a relação entre os dois interlocutores, em contraste com o que a narrativa cinematográfica, que parece ter optado, em geral, pela forma ele, que, de acordo com Émile Benveniste, caracteriza uma história narrada (histoire racontée). O olhar para a câmera seria a intervenção mor e a grande repressão da narrativa cinematográfica."6

(Vernet, 1989, p. 48)

O olhar para a câmera é recurso quase proibido dentro do cinema clássico americano. Empregá-lo sem um intuito estilístico é considerado erro, um lapso técnico; isso porque o olhar dirigido está diretamente ligado à quebra da ilusão de objetividade que o cinema clássico defendia. “Em particular por esse disfarce do discurso fílmico em história é que foi possível explicar a famosa regra que prescreve que o ator não olhe para a câmera" (Vernet, 1994, p. 121). A história é um enunciado puro, pelo qual se tenta pregar a ilusão de que ele se conta por si mesmo. A história, portanto, não 
admite dêixis, não admite marcas de enunciação, razão pela qual o olhar para a câmera, impressão explícita do eu no discurso, estilhaça de imediato a trucagem ${ }^{7}$ que ela opera.

O olhar para a câmera é em si mesmo um enunciado. A partir dele, o personagem salta a malha diegética e toma conhecimento de sua existência. Ao olhar para a câmera, ele não apenas diz; ele diz que diz. Como efeito colateral, o espectador também toma consciência de si. A partir do posicionamento do personagem enquanto personagem, o espectador é chamado a se posicionar enquanto espectador, e a ilusão da subjetividade é desfeita. Segundo Benveniste (1966, p. 84), “desde que ele se declara locutor e assume a língua, ele implanta o outro diante de si, qualquer que seja o grau de presença que ele atribua a este outro. Toda enunciação é, explícita ou implicitamente, uma alocução, ela postula um alocutário".

O personagem que olha para a câmera, mesmo que nada fale, está postulando seu lugar entre dois universos: o real e o diegético. Ele se proclama locutor e, ao fazê-lo, institui a figura do espectador diante de si. O espectador, até então absorto na história pela máquina fílmica que enseja a encenação da objetividade apagando as próprias marcas, não mais é um observador apenas, um ente invisível, que não se pode confrontar; não encarna mais na câmera como se a objetiva dessa fosse seu próprio olho. Ao chamar a atenção do espectador para sua condição de espectador, o enunciador devolve-o à realidade e à noção absoluta de que tudo ali não passa de um filme de ficção.

Se o olhar para a câmera, quando involuntário ou mal utilizado, é em geral condenado pelo cânone, seu uso enquanto recurso de estilo abre as mais diversas possibilidades de encenação dentro de um filme. É para investigar seus efeitos que olharemos mais atentamente para O demônio das onze horas (no original, Pierrot Le Fou), um filme francês de 1965, dirigido por Jean-Luc Godard. 


\section{O olhar para câmera por Jean-Luc Goadard}

Apesar de $O$ demônio das onze horas não ser a pedra fundamental da Nouvelle Vague nem ter inovado com rupturas na narrativa cinematográfica (papel desempenhado por títulos anteriores, muitos dos quais do próprio Godard, como O acossado, de 1960, e Uma mulher é uma mulher, de 1961), ele representa como nenhum outro o vigor insurgente de seus expoentes, a rebelião contra toda forma de regra que, na visão dos jovens diretores, apenas sabotava o artista em sua criação. Uma dessas normas atacadas é a que se vê em uma famosa cena de $O$ demônio das onze horas: Ferdinand (JeanPaul Belmondo) e Marianne (Anna Karina) dirigem um galaxy vermelho conversível; a câmera simula a posição do espectador, ocupando o banco traseiro. Subitamente Ferdinand olha para trás (para a câmera) e diz: "Tudo no que ela pensa é diversão". Marianne pergunta: "Com quem você está falando?", "Com a plateia" responde ele, enquanto ela repete o olhar direcionado para o olho da "plateia" citada por Ferdinand.

Quando Christian Metz argumentou que a enunciação no cinema é impessoal, falava que a relação benvenisteana eu/tu não podia ser aplicada de forma intacta à linguagem cinematográfica porque, em primeiro lugar, não há troca linguageira na dinâmica filme/espectador e, em segundo lugar, nunca se soube ao certo de que pessoa se trata o eu nessa equação. Como vimos, para resolver esse problema, Metz postulou que a enunciação no cinema não pode ser atribuída especificamente a um indivíduo, e isso em função da natureza colaborativa inerente a esta arte e porque ela emana do filme como um todo, de todo o processo de mise-en-scène operada não só pelo diretor, mas também pelos atores, pelo fotógrafo, pelo montador e todos os outros profissionais envolvidos na sua produção (ainda que esses estejam sob a ascendência da figura do diretor); logo, a enunciação é impessoal, ou seja, toma lugar na forma da terceira pessoa, do ele (não-pessoa); o discurso travestido de história. Opera-se um assalto à enunciação impessoal ditada pelo filme a partir do momento 
em que se transfere a fonte do discurso das mãos do objeto filme para um de seus personagens, trazendo assim uma ilusão de pessoalidade. Benveniste anota este tipo de trucagem:

Pelo fato de não implicar nenhuma pessoa, (a terceira pessoa/nãopessoa) pode tomar qualquer sujeito ou não comportar nenhum, e esse sujeito, expresso ou não, nunca é proposto como pessoa. Esse sujeito só faz acrescentar em aposição uma precisão julgada necessária para a inteligência do conteúdo, não para a determinação da forma."

(Benveniste, 1966, p. 253)

O demônio das onze horas volta-se contra esse preceito a partir do momento em que o personagem Ferdinand, ser fictício, habitante do universo diegético, executa três movimentos: [1] olha para a câmera (para o olho do espectador), [2] toma para si o discurso (transferindo-o, portanto, da esfera impessoal ele para a pessoal eu) e [3] o enuncia diretamente ao espectador (ou seja, postula um alocutário). Essa operação é radical por duas razões:

1. O espectador é chamado a tomar consciência de si;

2. A mensagem do filme não é mais transmitida pela instituição filme (que é impessoal) neste momento, mas pela personagem/pessoa Ferdinand.

Essa "pessoalização" do locutor do filme trata-se, evidentemente, de uma estratégia enunciativa, de um recurso de mise-en-scène. Mas com que objetivo? Contrariar esta eficácia do cinema clássico anotada por Marc Vernet. O cineasta francês desata laços com a narrativa clássica pelo simples ato de desatá-los, pelo fim em si. O único 
compromisso de Godard com seu filme é, por mais autocentrado que isso soe, seu próprio virtuosismo enquanto contador de histórias. Tal ação, contudo, escapa ao mero capricho ou vaidade. Para compreender este tour de force de Godard para dar jogar ênfase sobre a figura do diretor é preciso resgatar o contexto: foram os franceses da Cahiers du Cinéma, dentre eles o próprio Godard, que defenderam, de 1954 a 1964, uma "política dos autores" (Vernet, 1995, p. 110). Essa política visava a uma redescoberta de alguns diretores do período clássico e à promoção da própria Nouvelle Vague. Pode-se reconhecer então uma irresistível tendência dos diretores desse movimento (Godard, Malle, Truffaut, Chabrol, Rohmer) para marcar a si mesmos neste anseio e serem reconhecidos como "autores", no período em que ainda se buscava uma equiparação do diretor de cinema com o escritor e o pintor (a ideia de autor, hoje, é raramente utilizada tendo em vista que o cinema é uma arte concebida em colaboração com dezenas de profissionais).

Ao conceder a um personagem a consciência da existência da câmera, do filme, do espectador e da artificialidade do seu universo (que é diegético, fictício), Godard concede essa mesma consciência ao espectador. Ao perceber sua condição, o espectador vê quebrado o encantamento da atmosfera fílmica, a sensação de realismo e imersão que o cinema provê, e é forçado a ver o filme como filme, ou seja, como peça de ficção, como uma obra concebida por terceiros. Nesse caso, o objetivo (dentre outros) de Godard é chamar a atenção para os terceiros envolvidos nesta equação, ou seja, para a figura do autor da obra a que o espectador assiste. Godard atinge esse objetivo através da quebra da diegitização, através do rompimento do processo comum ao cinema clássico de vestir o discurso em forma de história. Como parte desta benigna ilusão cinematográfica concebida para "enganar", ou seja, para entreter o público.

Em $O$ demônio das onze horas, o olhar e a referência verbal à plateia não têm qualquer efeito sobre a diegese, não voltam a ser lembrados posteriormente na trama, 
contrariando preceitos da narrativa clássica que mandam não desperdiçar informação, não deixar, em linguagem de roteirista, "pontas soltas". Seu único resultado prático (do ponto de vista da linguagem clássica) talvez seja um traço tímido de humor, pela própria natureza subversiva do recurso, mas que se esgota subitamente. Seria gratuito, então? De modo algum; obedece ao caráter de manifesto dos filmes franceses da primeira metade da década de 60 , um manifesto pela autoria cinematográfica.

O olhar para a câmera, em $O$ demônio das onze horas, é marca do próprio diretor, aquele que se declara, por esse gesto, o locutor, o enunciador, o contador da história, com poder para alterá-la a qualquer momento. Ou seja, com poder autoral sobre seu relato. Como afirmou Metz (1972, p. 161), “certos processos cinematográficos só adquirem um sentido fixo com relação a sistemas fílmicos", e é o que ocorre com esse recurso quando posto em uso por Godard.

Godard emprega o olhar para a câmera como forma de chamar a atenção para a própria concepção do filme. Se pela acepção benvenistiana de história, o cinema clássico americano empenhava-se em apagar os vestígios de sua narração, Godard pretende que o espectador atente exatamente para esses vestígios. No que o cinema clássico é história, O demônio das onze horas é discurso.

\section{Considerações finais}

A questão do olhar para a câmera, um marco enunciativo proeminente, é ampla e muitos outros casos poderiam ser trazidos à tona. Há, entre outras possibilidades de estudo, a ruptura que o próprio cinema americano começava proceder com o cinema clássico, a partir da década de 70, com o surgimento da geração conhecida como Nova Hollywood, composta por diretores como Michael Cimino, Martin Scorsese, John Cassavetes, Peter Bogdanovich, Brian De Palma, Francis Ford Coppola, entre outros. 
Nossa questão norteadora chamou a atenção para usos e efeitos que o olhar para a câmera, enquanto recurso de que dispunha o diretor de cinema, poderia ter na prática de um ponto de vista da enunciação. Verificamos que o olhar para a câmera é usado por Godard para chamar a atenção do espectador para o aspecto extradiegético do filme a fim de fortalecer a figura do diretor de cinema, tomando-se o contexto da época em que os jovens cineastas franceses da Nouvelle Vague empunharam a bandeira da política dos autores, cunhada por André Bazin, e a agitaram não somente em artigos da Cahiers du Cinéma, mas principalmente em seus filmes ao longo da década de 60 (sobretudo em sua primeira metade).

O assunto, porém, conforme pontuamos, está longe de ser esgotado. Falta investigar a ocorrência de outros casos, incluindo quando o recurso é usado não para instituir um argumento extrafilme, mas para funcionar como elemento narrativo. Também mostra-se relevante o olhar para a câmera que não é endereçado ao espectador, mas que apenas o atravessa e atinge outro personagem. Não há gratuidade em escolhas de estilo. Por que razão o diretor decidiu que seria mais eficiente se o olhar passasse pelo espectador antes de chegar ao personagem a quem era originalmente dirigido? Perguntas como essa demandam uma resposta.

O olhar para a câmera é um grito enunciado, um chamamento do filme ao espectador que ultrapassa as camadas do universo diegético, desfaz a ilusão da sala escura, tão cara ao cinema, e convoca-o a estabelecer uma relação muito mais profunda do que a do espectador/personagem. Através do olhar para a câmera, o cinema atinge níveis de ênfase que a própria arte, ao proibir um de seus mais potentes recursos, sabia possível.

\section{REFERÊNCIAS}

AUMONT, Jacques et al. A estética do filme. Campinas: Papirus , 1995. 
BENVENISTE, Émile (1966). A Natureza dos pronomes. In: Problemas de linguística geral 1. Campinas: Pontes, 1995.

CASETTI, Francesco. Inside the Gaze: The Film and Its Spectator. Bloomington-Indianapolis: Indiana University Press, 1991.

CINTRA, Ismael Ângelo. Marcas linguísticas do narrador. Revista Alfa, São Paulo,v. 25, pp. 49-56, 1981.

CHARAUDEAU, Patrick; MAINGUENEAU, Dominique. Dicionário de análise do discurso. São Paulo: Contexto. 2008.

DIXON, Wheeler Winston. It looks at you: the returned gaze of cinema. Nova York: Sunny Press, 1994.

GARDIES, René. Compreende le cinema et les images. Lisboa, Portugal, 2006. Disponível em: <http://www. olivreiro.com.br/pdf/livros/cultura/2661452.pdf>. Acesso em: 21 ago. 2011.

GAUDREAULT, André; JOST, François. Enunciation and narration: a Companion to Film Theory, 1999. Disponível em: <http://www.film.uzh.ch/download/lehrveranstaltungen/filmtheorie/Enunciation.pdf>. Acesso em: 21 ago. 2011.

METZ, Christian. Linguagem e cinema. São Paulo: Perspectiva, 1971.

. A significação no cinema. São Paulo: Perspectiva, 1972.

. The Impersonal Enunciation, or the Site of Film (in the margin of recent work of enunciation in cinema. New Literary History, The Johns Hopkins University Press, v. 22, pp. 747-772, 1991.

VERNET, Marc. The look at the camera. In: Cinema Journal. Texas, 1989. Disponível em: <http://www.jstor. org/pss/1225117>. Acesso em: 21 ago. 2011.

\section{NOTAS}

1 O cinema praticado nos EUA, por diretores americanos ou não, da década de 20 até o final da década de 50 (o epílogo desta fase costuma ser apontado pelos críticos como o filme A marca da maldade, 1958, de Orson Welles).

2 História aparece aqui em oposição a Discurso, segundo consagrada oposição de Benveniste. O linguista define história como "a apresentação de eventos em algum ponto do tempo sem a intervenção do locutor no relato". Discurso, por outro lado, é "qualquer pronunciação supondo um locutor e um alocutário em que haja a intenção de influenciar o outro de alguma maneira" (apud Cintra, 1981, p. 51). Eleva-se de imediato, portanto, a questão da objetividade e da subjetividade do récit.

3 Em cinema, é o "colocar em cena" pelo diretor. Suas escolhas técnicas e criativas para narrar através da apreensão do campo e dos atores pela câmera. 
4 Um derivado do gênero americano de faroeste das décadas de 40 e 50, praticado por diretores italianos a partir dos anos 1960, já durante a crise de popularidade do western junto ao grande público americano.

5 "Nova Onda". Movimento do cinema francês surgido no final dos anos 50, tendo como principais expoentes os ex-críticos da Cahiers du Cinéma: Jean-Luc Godard, Louis Malle, François Truffaut, Jacques Rivette, Eric Rohmer, Claude Chabrol, entre outros.

6 [Nossa tradução] it is supposed traditionally that the discursive form "I/YOU" comes to accentuate the relation of the two interlocutors in contrast to narrative cinema that would seem to have opted in general for the form "he", which, according to Émile Benveniste, characterizes a narrated story [histoire racontée]. The look at the camera would be the "major interdiction" and the great "repressed of narrative cinema".

7 No cinema, o processo pelo qual se cria uma ilusão ou um efeito especial. Sua história começa com os curtas de Georges Méilès, do início do século XX.

Recebido em: 15 jul. 2013

Aceito em: 10 mar. 2014

\section{Endereço do autor:}

Ernani Cesar de Freitas <ecesar@upf.br>

Instituto de Ciências Sociais Aplicadas - ICSA

Universidade Feevale Novo Hamburgo

Rodovia RS 239, n. 2755 - Vila Nova

93352-000 Novo Hamburgo, RS, Brasil 